\section{Microbial biology}

Microbial ecology is a difficult subject to teach, being concerned with complex biological interactions and relying on diverse expertise for its investigation. Dr R. E. Campbell in his book Microbial Ecology (Blackwell Scientific: Oxford, paperback $£ 4.25$ ) states that he has chosen to view the subject in terms of communities of interacting organisms, rather than form a physiological standpoint. Having made this point, he then proceeds to an excellent short survey of microbial ecology, which by its very nature must include detailed consideration of physiological processes. The testing of reactions in the carbon cycle ( 221 ), the discussion of cellulose metabolism (p25), and the accounts of nitrogen fixation (pp44-45) and of the activities of microorganisms in sulphur conversions ( $p 55$ ), are only a few of the many physiological and biochemical topics whose significance in an ecological context is clearly defined by the author.

The book is divided into nine chapters. The first two are introductory; these are followed by three on the carbon, nitrogen, sulphur and other chemical cycles. The structure and dynamics of microbial populations in soil, water and air are covered in three chapters, and there is a final short conclusion. Within this compass, Dr Campbell has been able to include almost all that most microbiologists would expect in an introductory text.

The first chapter, a short introduction, includes a section on methods of study (plating, ATP and so on) and on modelling. Both can only titillate the more motivated student. "Ecosystems are never static", the first sentence of chapter 2, leads the reader directly into the basic concepts of energy flow, food chains and trophic levels, which are covered without enough specific examples to my mind, but are presented in a chatty style. If you like this approach, the chapter will please. I felt more at ease in chapters 3, 4 and 5, in which $\mathrm{Dr}$ Campbell describes the various chemical cycles (carbon, nitrogen, sulphur, phosphorus, iron, manganese and silicon). Students will undoubtedly find the clear figures and diagrams useful. Figure 4.1, the global nitrogen cycle, and Table 5.1, sulphur conversions, are particularly good, although the print is a little small in some places (for example, Figure 4.5). The degradation of manufactured materials, and biocides in the carbon cycle, are also discussed in two short sections.

Chapters 6,7 and 8 concentrate on the diversity of types of naturally occurring microorganisms in soil, water and air. In these chapters enough ecological background is presented for the novice reader to understand why particular microbiological investigations are important.
As a single example, the significance of soil water supplying nutrients and possibly causing anaerobiosis is discussed on p64. There are also interesting discussions on the rhizosphere around plant roots, biological control of soil-borne pathogens, eutrophication and pollution, air inside and outside buildings, and the microbiology of animal surfaces.

Personally, I like the book, and know of no other having such a broad coverage and simple presentation. For the serious student, there are reading lists at the end of each chapter, and comprehensive species and subject indexes; he has, therefore, no need to complain that the subject treatment is too superficial. The book is excellent value.

Professor M. Alexander has produced a second edition of his Introduction to Soil Microbiology (Wiley: New York, London and Sydney, £13.50; \$23) which he has brought up to date and also modified by considering how soil microorganisms cope with the effect of man (pesticides, pollutants), and what toxicants they produce in soils. The dust-cover considers the book to be an introduction and "ideal for beginners"; however, its cost and length (467 pages), suggest that it should be considered more properly as an advanced undergraduate or postgraduate text. Detailed reading proves this to be so, and one could quote many examples. There are, for instance, ten pages devoted to hemicelluloses besides fourteen on celluloses, and an advanced account of the biochemistry of hemicellulose decomposition (pp171-172), all of which are hardly ideal for beginners, although first-rate expositions. Having said this, the book is an excellent source for the specialist or advanced student: I

\section{Plant pathology}

Plant Pathology and Plant Pathogens. By C. H. Dickinson and J. A. Lucas. Pp. 161. (Blackwell Scientific: Oxford, London, Edinburgh and Melbourne, 1977.) $£ 4.25$.

THIS introductory plant pathology textbook adopts the approach of a general treatment of principles without detailed consideration of individual diseases. An appendix is included giving cross references to other books for this detail. An adequate microbiological background must be assumed, although the authors have sometimes defined simple terms such as mycelium and given little or no explanation of more difficult ones such as teleutospore.

The text moves from general introduction to infection and colonisation, hostpathogen interactions from population to molecular levels, and finally control. Physiological and molecular interactions are treated in some detail, even in relation to still unresolved problems, such as the concept of hypersensitivity. Conversely, was not well informed on the acetylene reduction technique for nitrogen fixation and found it summarised on p288, nor was I aware of modern views concerning lignin decomposition which Professor Alexander discusses fully.

The book is divided into five parts. The first is a basic description of the taxonomic groups of microorganisms found in soil. The second and third are detailed treatments of the carbon and nitrogen cycle, and cover 190 pages. There are many important topics included here, such as the microbiology of polysaccharides, nitrification and organic matter decomposition. It is possible to argue that the chemical pathways of benzene ring cleavage (p219) and purine metabolism (p236) are available in standard chemical texts; however, many students will find their inclusion helpful. There follows a section on mineral transformations in which the metabolism and fate of phosphorus, sulphur, iron, and heavy metal pollutants are considered. I was particularly interested in the discussion of mercury, selenium, and arsenic in soils. The final part of the book is called "Ecological Interrelationships" and includes chapters on interactions among species, the rhizosphere, and pesticides.

In general, I found Professor Alexander's book a well written advanced text on soil microbiology with excellent literature references, and can recommend it as a straightforward account interlaced with many references to areas of doubt that should suggest research topics to the motivated student or postgraduate.

P. S. Meadows

P. S. Meadows is Senior Lecturer in Zoology at the University of Glasgow, Scotland.

well established areas such as epidemiology and chemical control are treated relatively superficially. The authors tend to undervalue the contribution of the agrochemical companies to successful disease control and to the avoidance of toxicological and environmental hazards. The "Integrated Control" section, on the other hand, hardly warrants the prominence given it in the publisher's note. The text is well illustrated with diagrams and electron micrographs but has few illustrations of pathogens or diseases of the kind that would help the student to develop a feeling for what plant diseases are like.

These considerations apart, however, the book is clearly, concisely and interestingly presented and helps fill the gap between the short Institute of Biology Studies in Biology type of format (Arnold: London) and the heavy textbook. Undergraduates should find it useful, especially if they combine it with a study of individual diseases from other texts or from practical work.

I. M. Smith

I. M. Smith is Lecturer in Plant Pathology at Imperial College, London, UK. 